\title{
Music in the time-spectrum: Routines, spaces and emotional experience
}

\begin{abstract}
Music streaming, structured by an expanding network of social interdependencies (e.g. musicians, sound engineers, computer scientists and distributors) has made it easier to consume music in a wider number of social and private spaces and to a greater degree. This paper examines the emotional experience of contemporary music consumption by drawing from an Eliasian perspective, specifically Elias and Dunning's sociology of leisure. We explore the relationship between work, sparetime and leisure spaces, rather than examining specific spaces in isolation. We argue that music is used to demarcate, transition between, and blur space. Music plays an important role in facilitating the rhythm of routine, helping individuals to adjust to the demands of different spaces (based on varying intensities and immediacies of social pressures) and manage mood. The key characteristics of leisure that Elias and Dunning identify (motility, sociability and mimetic tension) are explored across the spectrum of time and space.
\end{abstract}

Keywords: Music streaming, figurational sociology, sparetime spectrum, work, leisure 


\section{Introduction}

The digitisation of music consumption has created considerable structural upheaval in the music recording industry with subsequent discussion on piracy (Giesler, 2008) and the moral quandaries the music consumer faces as a result of increased opportunities to download and share music without financial or legal risk (Rojek, 2005). Furthermore, there has been an emphasis on the aesthetic transformation from physical to digital formats and associated questions around materiality and ownership (Magaudda, 2011; Author A and Author B). However, such discussion has somewhat distracted attention from important questions concerning how changes in music consumption have impacted upon social life. The British Phonographic Industry (2017) has reported annual increases in the volume of music that is consumed since the introduction of music streaming applications (e.g. Spotify, Apple Music) to the mainstream commercial market. A higher volume of consumption is attributable to greater mobility and instant accessibility to music. Mobile technologies have made it easier to consume music in a wider number of social and private spaces and to a greater degree. However, they have also blurred the distinctions between different public and private spaces and complicated our understanding of how people use music to demarcate and manage space and mood.

This brings us to the first objective of the paper. Elias and Dunning's (2008a) sociology of leisure, and in particular their work on the sparetime spectrum, is used in this paper to theoretically frame contemporary music consumption experiences across a variety of spaces. Space and time are not considered in isolation in figurational sociology and Elias and Dunning's framework explores sport and leisure in the context of broader processes such as industrialisation, urbanisation, commercialisation and rationalisation and changing power 
balances between social classes. They demonstrate how important leisure has become over time in line with structural transformations, expanding chains of social interdependencies and increasing social and individual restraints. Sport and leisure offer people a chance to engage in a mimetic, controlled de-controlling of emotions in response to routinisation processes. For Elias and Dunning (2008b), routinisaton refers to the subordination of feelings and impulses due to the need to perform functions for others as an aspect of one's social position; routines are less selforiented compared to emotionally pleasurable leisure pursuits. While Elias and Dunning (2008b) acknowledge the overlap between work and the sparetime spectrum, there is little exploration of how ostensible leisure activities (emphasis on music) have permeated traditional non-leisure spaces. Similarly, while technologies of mobility are recognised as being able to create opportunities for increasing integration of leisure into a greater variety of spaces there have been considerable changes to the nature of work and leisure since Elias and Dunning published their work three decades ago (comprising essays and articles published from the 1960s to the 1980s, and see also a recently published manuscript on leisure and spontaneity originally presented by Elias in 1957 (Elias, 2018)). As such, this brings us to our second objective where there is an opportunity to revisit Elias and Dunning's sparetime spectrum to develop a contemporary discussion on the changing meaning of leisure via the context of contemporary music consumption. The broader discussion concerning the changing meaning of leisure is articulated through our exploration of how people use leisure (i.e. music) to manage different spaces and the implications thereof.

Following three stages of data collection (with UK and Irish participants) that included discussion groups, in-depth interviews and tracking surveys we outline how emotional tension is 
generated, managed and articulated through contemporary music consumption across a spectrum of spaces. We place emphasis on key themes of choice, management of space and mood.

\section{Emotion, music and routines}

Previous research has underscored the functionality of music (Merriam, 1964) and the ways in which it impacts the mood and performance of individuals in a particular space or a given task. Schäfer, Sedlmeier, Städtler and Huron (2013) identify 129 different functions of music but they place emphasis on its use for regulating arousal and mood. Hargreaves and North (1999) examine the role of music as a means of mood management in their seminal study of music and everyday life, using examples such as the playing of slow music to stay calm during a traffic jam or to make others comfortable by playing music they are familiar with. They link these findings to the psychological implications of technological change at a time when increasing access, mobility and cheaper recording technologies only began to emerge as distinct possibilities. This research has influenced subsequent studies concerning music consumption and cognitive performance (Sloboda, 2005) and its role in particular tasks such as travelling (Heye and Lamont, 2010) and exercise (North and Hargreaves, 2000).

The instrumental focus regarding music's impact on the individual is nothing new. For example, studies have documented the role of music as a means of social control in the workplace. Jones and Schumacher (1992, p. 162) examine how music is used to promote 'factory good will' and Oldham, Cummings, Mischel, Schmidtke and Zhou (1995) comment on the use of music to improve productivity and alleviate tiredness. Adorno would argue that such a view of music consumption typifies the 'culture industries' and the standardisation of music as a capitalist product that has numbed critical engagement (Adorno, 2006). DeNora (2000) has framed 
Adorno's views on music consumption as somewhat elitist and Gregory (1997) argues that he is dismissive of the emotional value of music, regardless of the genre or context in which it is consumed.

DeNora (2000) acknowledges the social power that comes with controlling the production and consumption of music. However, she maintains that individuals use music as reflexive subjects and places emphasis on the agency of the individual in shaping identity, relationships and mood. Music is an 'active ingredient in the organization of the self' (2000, p. 61). DeNora demonstrates this reflexivity through exploring how actors use the 'audio-environment' to make sense of and negotiate a variety of social contexts from an intimate setting with a loved one to retail spaces and exercise classes. Bull $(2000,2006)$ frames contemporary music in a similarly empowering fashion, focusing on the increased mobility of consumption afforded to early users of the iPod and the Walkman. He describes how the mobile consumption of music is used to block out the sounds of the city, construct a personal soundtrack/scape, control emotions, establish social boundaries through use of headphones and generally to transform 'mundane daily experience into one of personal significance and meaning' (Bull, 2006, p. 135). Bull's celebration of the mobility and increased choice afforded by the introduction of the iPod is illuminative of the changing nature of how we interact within different social spaces with music. However, the emphasis is on individual spaces and tasks. There is little discussion of how music facilitates the relationship between these spaces. In the next section we will continue to develop upon such themes through an Eliasian lens, and in particular Elias and Dunning's (2008a) sociology of leisure.

\section{Figurational sociology of leisure}


Elias and Dunning (2008a) consider the historical relationship between work and routinised practices on the one hand and leisure spaces on the other, in which participants and spectators of sport (and other leisure activities) can generate and release emotional tension. They argue that increasing industrialisation and expanding social interdependencies imposed greater social constraints towards a more even emotional self-control, and thereby generated a greater need for emotional excitement. This socially generated need led in the nineteenth century to the formalisation of previously chaotic and violent games such as folk football. This organisation of leisure allows for spaces in which a 'controlled de-controlling of emotions' Elias (2008, p. 27) could take place. Author A and Author C describe the evolution of extreme music subcultures through this Eliasian lens as enclaves of controlled chaos, demonstrating that these ideas can be extended to other 'leisure' activities beyond sport (see Dunning, 1997), which has tended to warrant most attention from figurational sociologists.

Adopting this theoretical framing in the context of contemporary and increasingly mobile music consumption practices raises interesting questions regarding the nature of leisure and whether music can be defined as such. Elias and Dunning (2008b) suggest that leisure activities usually fall into at least one of three forms. They are sociable activities, involve motility and create tension through imaginary and/or controlled means. Maguire (2011, p. 922) argues that the 'scope for the exercise of the imagination involved [in sport] appears to be of a rather restricted and heavily-rule-bound [compared to the arts] kind'. Music can be viewed as a leisure activity as it often involves sociable activities, and it sometimes involves motility and a sense of mimetic tension. However, can it be considered as leisure within these constraints when it is consumed in different types of spaces? For example, there has been a greying of spare/non-spare time and activities. Consumer fan productivity/labour is often cited as key in establishing and enhancing 
leisure products/services in sport, tourism and in particular the arts, making categorisation of work or leisure more difficult.

Elias and Dunning argue that leisure has previously received a lack of attention from sociologists because it was viewed as simply an adjunct to work. Contemporary research still frequently frames the relationship between leisure and work in this way. For example, evidence suggests that despite the move towards increasingly flexible work hours (depending on the sector), we still work longer hours and as a consequence there are higher reported levels of stress in the workplace (see Chartered Institute of Personnel and Development, 2016). This has placed a greater emphasis on leisure as a means of facilitating psychological detachment from the workplace (see Sonnentag, Arbeus, Mahn and Fritz, 2014). However, this distinction is too simplistic. Elias and Dunning identify the shades of grey between leisure and non-leisure activities arguing against the misguided presumption that all non-work time is leisure. They developed a sparetime spectrum to differentiate between 'sparetime routines' (e.g. catering for one's biological needs, household cleaning), 'intermediary sparetime activities' (voluntary work, hobbies) and defined leisure activities (e.g. sport, music) (Elias and Dunning, 2008b). These divisions within the sparetime spectrum are related to the routines of non-sparetime spaces which they describe as:

recurrent channels of action enforced by interdependence with others, and which impose upon the individual fairly high degree of regularity, steadiness and emotional control in conduct and which block other channels of action even if they correspond better to the mood, the feelings, the emotional needs of the moment. (Elias and Dunning, 2008b, p. 80). 
In other words, the non-sparetime spaces are generally highly routinised and require high levels of emotional regulation. The different levels of the sparetime spectrum address the emotional needs created by the non-sparetime spectrum to varying degrees but it must be acknowledged that activities within the sparetime spectrum (e.g. sparetime routines such as grocery shopping) are also subject to routinisation and high levels of social compulsion. The aesthetic interest that is apparent in the behavioural dichotomy of work-leisure means that much of the empirical research has focused on this third category of 'defined leisure activities' where a controlled decontrolling of civilised norms occurs (e.g. Author A and Author C).

However, empirical research is needed which considers the relationship between leisure and routine across a greater variety of spaces. This is important when we consider how broader structural transformations have influenced the nature of both spare and non-spare time spaces and the relationships over the spectrum. Technological, economic and social transformations have undoubtedly altered the work place (Thing, 2016), blurring what work is or is not (Stebbins, 2015). Consequently, how contemporary music consumption infiltrates sparetime and nonsparetime spectrums is under-researched. Similarly, how this impacts on the way in which people use music to manage and demarcate space and ultimately manage their emotions across the time spectrum warrants exploration.

\section{Method}

In this study we place emphasis on how participants experience music in a variety of spaces/activities and the transitions between these spaces, collecting data using a three-stage approach. A marketing research company was used to recruit 19 participants for an online themed discussion forum. Purposive and snowball sampling strategies (Merriam, 2009) were 
used to recruit 25 participants from Ireland and Scotland for in-depth interviews. An informal tracking survey was conducted on nine of the interviewees. The criterion for sampling was that the participants had experience of using music streaming platforms (both premium and freemium formats). There is a relatively equal gender split (19 female and 25 male) and the participants ranged in age from 18 to 34 . This sample represents the age group that use streaming applications most frequently. Small incentives in the form of vouchers were used to thank participants for their time.

\section{Online themed discussion group}

The discussion took place over the course of a week with specific themes dedicated to each day. Examples included music and emotion, music and space, ownership and artist compensation. Although these themes were introduced in a structured manner during the course of the week, the participants were encouraged to debate amongst one another with the researchers providing guidance if the discussion went off-topic. Individual participants were messaged privately to encourage them to elaborate on certain points without interrupting the flow of the group discussion or enabling the domination of the discussion by specific individuals. There were over 400 posts and the transcripts were reviewed by the authors in order to develop a number of themes (e.g. mobility, space, choice and empowerment) which were used to develop the topicguide for the interviews.

\section{Interviews and informal tracking survey}

The first phase of interviews were semi-structured, focusing on a number of themes concerning the particular formats participants used to consume music, how they find new music and issues regarding quality and quantity. A key theme that emerged from these interviews, as well as the 
discussion group, concerned how the participants used music to control mood and manage the different spaces they encounter in their everyday lives. Consequently, the final nine interviews explored this theme in far greater detail, using informal tracking surveys in the two weeks leading up to the interview. This allowed participants to comment on where and when they were listening to music, what they were doing, who they were with (if anyone) when they were listening, the reason for listening to music and the $\operatorname{mood}(\mathrm{s})$ they experienced at the time. Pink and Fors (2013, p. 380) discuss how such methods can be used to visualise and verbalise the 'usually unspoken elements' of our interaction with technologies, making such accounts 'accessible to us as researchers'.

Each participant received a short questionnaire and a request to create a playlist which reflected their current mood six times over the course of the two weeks. The surveys were sent at alternating times for each participant to capture data from the different spaces they occupied throughout the day. The participants were able to use their phones to respond to each questionnaire instantly. The questionnaire (discussed in the interview) encouraged participants to reflect on their daily use of music and enhanced the interviews that took place at the end of the tracking survey.

\section{Findings}

The findings are organised as follows. First we provide a descriptive account of the experiences of the participants and their increasing access and choice in consuming music through streaming applications. Following this we explore the impact of increasing mobility in consumption and consider how music is used to control mood. In each theme we describe how emotional tension is generated, managed and articulated through music across a spectrum of spaces. 


\section{Choice}

The participants predominantly consume music via streaming applications, in particular Spotify. Streaming applications have increased the potential level of choice that is available to the contemporary music consumer because of the large number of songs that can be now accessed easily on mobile devices (Wlömert and Papies, 2016). The participants report listening to music in higher volume, with greater convenience and in a wide number of spaces (more on this in the next section). This section will discuss the implications these changing practices have on the quality of the emotional tension experienced through consumption.

Although, the participants still listen to music via the radio, CDs, vinyl and other mediums, streaming has increased the amount of content that participants consume:

Without doubt I listen to more music since you were able to stream it. If I am online I can just go on YouTube and have music on in the background while I'm working or doing other stuff. While I still use radios and CD players along with my iPod, having the extra option of streaming means I can listen to music all the time if I choose to. (sheepcm, 2534)

Participants have access to data systems which track and inform the listener of what they are listening to and when. This heightens the experience of choice:

LastFM has me tracked as listening to over 20,000 tracks in the last year, just over 1,700 hours of listening time, so around 4.5 hours a day. That's only time spent on a PC (so home and work), it doesn't track what I'm listening to on the move. (Wnand, 25-34) 
The amount of music that participants have access to is facilitated by increasingly integrated social media interdependencies that exist for the purposes of sharing information about new music and website/application links which can bring the user access instantaneously:

We (my close-knit group of friends) have a group chat on WhatsApp which we all contribute to posting new music we find. Whether it be tracks or mixes. Same with Facebook or Twitter. I share mainly on Facebook, posting links from sites such as Soundcloud, Beatport, Traxsource. Occasionally BBC Radio 1. (Blue_lagoon, 25-34)

Elias (2012) explains how social conduct changes (e.g. towards more individualised self-steering dispositions and less emotional volatility becoming part of the habitus) within the context of increasingly complex social interdependencies. Individuals here become enmeshed in denser figurations of existing dependencies which have become more intensive in that the function of the group and its associated activities such as discussing and sharing music has increased. This can lead to a rapid change in music or subcultural taste (see Author A and Author C):

I think it [WhatsApp group dedicated to music] probably does encourage us all to seek out new music as when one person starts it tends to get the ball-rolling and other followup with posts containing their own suggestions. (Blue_lagoon, 25-34)

The increase in quantity of music is not necessarily a positive experience for all the respondents. First, there is a quality issue with the technical impact associated with hosting a significant amount of music on individual applications (e.g. Spotify). Participants who consumed a high volume of music and considered themselves 'audiophiles' could discern the difference between a song played via $\mathrm{CD}$ and a digital track that is streamed: 
Storage space is important on servers so they cut back on quality and also this releases their networks bottleneck and keeps the service running....So quality is the price for speed and storage. (Kithi, 25-34)

The difference in quality to the average ear is indiscernible, but the high level of choice has a more profound, almost numbing impact on many of the respondents' experiences of listening to music. Sean outlines his frustration with his growing impatience when listening to music:
Albums are sort of dead to me. I remember buying albums and listening to them and going "that's a great song, that's not as good, that's brilliant." You know, whatever it was. And you almost judged that entire album. But now it's like you're ten, twenty seconds into a song and you're not feeling it you can just skip it because there's loads of songs, millions of songs, you can listen to. And why would I waste my time with four and a half minutes of that when the first thirty seconds are shite? ... So I think we're just becoming impatient as well. (Sean, 34)

This desire for instant gratification and an 'all killer, no filler' type of music consumption was a common theme of frustration with the participants who longed for the days when they had the patience to listen to an entire album, defer gratification and build a sense of tension. Elias and Dunning (2008a) argue that enjoyable tensions experienced through the structured dynamics of leisure are key to its emotional function. This is perhaps lost in some way given the vastness of the Spotify back- catalogue when searching for that 'kick' that a boundless number of songs surely promise. Léveillé (2017) documents the decreasing attention span of music consumers and its impact on pop music songs where intros have reduced from an average of 20 seconds in the mid-1980s to an average of 5 seconds. Léveillé argues that this is a product of the increasingly 
competitive 'attention economy'. However, the participants also demonstrate a propensity for managing the 'stress' of too much choice by developing strategies of control that allow them to navigate the music available to them. Psychic energy is placed into learning how to manage user interfaces of streaming applications, create playlists and organise consumption through genre, artist, mood and even space (see Author A and Author B). This is what DeNora (2000) refers to as the organisation of the self through music. From a figurational perspective, it is a partly unplanned social constraint towards self-steering conduct, once we recognise the technical presentation of music products through the internet as actually the material and symbolic manifestation of complex social processes and interdependencies of the figuration comprising all the people involved in the movement of music from artistic conception to listening (from musicians, distribution managers, computer scientists, music publishers, artist managers, to name some of the functionaries involved in producing and distributing music through the web, all the way to consumers). While Elias and Dunning focused on the increasing complexity of social figurations in general through developing special enclaves of leisure oriented towards the generation of emotional tension, here we highlight changes in the specific figuration involved in producing and distributing music that adjust the potential and practices of emotional tension. We stress, however, that this more specific figuration still operates within broader figurations.

The increasing level of choice and volume of consumption has clearly had implications for the quality of emotional tension that the participants experience from music and is evident in the strategies they use to navigate their music consumption. However, to further understand how this tension is managed and to explore other key characteristics of music as a form of leisure (i.e. motility, sociability) we need to examine how music is consumed in a more contextual sense 
than has been discussed thus far. Consequently, the relationship between contemporary consumption and space is discussed in the next section.

\section{Space}

Research on music and space normally considers its consumption in particularly defined spaces such as the workplace (Jones and Schumacher, 1992) and leisure-time oriented live events (Halnon, 2004). Bull (2006) emphasises the increasing mobility of music consumption and the importance of objects such as the iPod in allowing people to take control of their music consumption in a variety of spaces where it was previously difficult to do so (e.g. commuting, the workplace). The increased mobility afforded to individual listeners by music streaming applications complicates the boundaries between spaces and means that there is not only a need to understand how music is used in specific spaces but how it traverses different but connected social spaces. Elias and Dunning's (2008b) sparetime spectrum (and its relationship with the non-sparetime spectrum) is used as a means of framing music consumption in the different spaces to understand its emotional significance. The use of the word spectrum is important here

as 'the various types of sparetime activities, like colours in the colour spectrum, shade into each other; they frequently overlap and fuse' (2008b, p. 77).

\section{Demarcation and transition: Non-sparetime activities}

The participants use music to demarcate and transition between spaces. A feature of contemporary consumption is the individualised nature of it as a consequence of the increasing prevalence of earphones. The simple use of earphones draws boundaries between social and personal spaces, notwithstanding the fact that the felt need for personal space is itself socially 
formed. This begins for many in the commute where the presence of earphones acts as a signal of departure from social engagement:

It's like an automatic thing now. You have an iPhone or a smartphone with music on it, it's like you automatically put them in the minute you get on a bus or whatever to work. (Audrey, 30)

The earphones not only facilitate the individualisation of space but also provide a medium through which the vast catalogues of music provided by streaming applications can be consumed. Specific playlists are created by the participants to generate the required mood for transitions between spaces that have become highly routinised (i.e. to wake up in the morning and wind down on the way home from work). Eoin compares the differences in listening practices in his free time to his commute:

E: There'd definitely be a bit of a separation between what I'd listen to at home or by myself than what I'd listen to when I'm on the way to work or on the way back.

I: What would that be?

E: I listen to more new music if I'm by myself at night or that. If somebody had told me something during the day I'd have gone home and investigated it that night. And as well as that I want to listen to something that's familiar when I'm just waking up in the morning [on the way to work]. (Eoin, 29)

Eoin has created a distinction between non-spare and sparetime spaces through his selection of music. However, the use of music within the commute can also be characterised as leisurely in the Eliasian sense as it can be used as means of escape from the mundanity of the commute and 
the non-sparetime routine. Music is also used to demarcate and transition into other spaces such as in work and sparetime contexts. For example, participants describe using earphones to shut themselves off from others in the work-space in order to focus on a particular task. The participants work in office jobs within the service economy which represents a change from the extant music literature (e.g. Korczynski and Jones, 2006) which considers the role of music as a controlling agent in the industrialised workplace. While Elias and Dunning acknowledge that it would be possible to develop a spectrum of non-sparetime occupations that focuses on the degree of opportunity of 'enjoyable emotional resonance' within occupations (2008a, p. 78), there is no exploration of what happens when leisure activities infiltrate into traditionally non-leisure spaces. The main difference in this largely non-industrial worker sample is that workers have more of an opportunity in which to listen to music at work because of new mobile technologies and more flexible working practices. However, this is dependent on the nature of interdependencies involved in particular work functions at particular organisational levels:

We can plug in headphones to our computer if we've got report writing and stuff to do. I haven't done it yet, even though I keep meaning to do it. But I just find the whole workplace, it's so open plan, even if you've got your headphones in your phone will ring or someone will try and speak to you, so I just haven't bothered doing it. (Ciara, 28)

For those who do consume music in work it can serve a functional role oriented towards the completion of tasks for co-workers or customers. Niall describes when he listens to his carefully selected acoustic playlist: 
I would most likely be listening at work with important things to do. Where I can have that as a background and it won't necessarily interrupt what it is I'm trying to achieve. I can focus on the tasks I have to do while listening to that music. (Niall, 28)

In this context music is not a leisure activity as it is orientated towards occupational performance for others and does not involve any of the characteristics of sociability, motility or mimetic tension that are associated with leisure activities. Many of the participants use music in this occupational way but also use it in somewhat of a leisurely fashion, whether that is in the commute or in opportune moments when they are not busy at work, when the social pressures normally heightened by position within the work figuration recede as demands from others temporally decline. As such, the functions of music in official work spaces oscillate depending on the rhythm and intensity of demands flowing through others comprising the figuration. The mobility afforded by streaming applications provides opportunities for micro moments of deroutinisation throughout the day. Gordon describes listening to music when going for a walk during a stressful work day:

It would as a stress reliever; it is a good reliever to stop you from punching someone in the head. (Gordon, 29)

Communal consumption of music in the office space can also create similar moments of deroutinisation and also indicate a more informal, leisurely and sociable atmosphere than accounts of the role of music in industrial factories (Oldham et al., 1995) where emphasis is on production and efficiency:

I'm a trainee accountant, so it's no music in the office where I am. But my previous job there was a radio on in the background and it was that more light-hearted, it wasn't as 
rigid. It felt more relaxed in that job. Where I am now is very strict and very professional. (Audrey, 30)

Mobile music technologies have created opportunities for consumption in non-sparetime spaces and there is evidence of the characteristics of sociability, motility, imagination and emotional tension we associate with leisure at work to a certain extent. However, the engagement with music as a leisure activity is more evident as we move down Elias and Dunning's sparetime spectrum.

\section{Blurring of space: Sparetime and intermediate activities}

It is important to acknowledge that not all non-work activities/spaces can be seen as leisure. Many of our sparetime activities are also highly routinised. Elias and Dunning refer to biological needs and domestic duties in particular. Furthermore, intermediate activities - activities that serve the purpose of orientation and/or self-fulfillment (e.g. volunteering, exercise), also involve a degree of routinisation, although to a lesser extent than sparetime routines. Elias and Dunning mostly focus on different activities that characterise the various aspects of the sparetime spectrum. Music is often highly integrated into a number of sparetime routines and is very rarely consumed in isolation from other activities:

If I'd iron a shirt the night before I'd go to work I'd listen to something an awful lot calmer when I was doing that or doing the dishes or cooking or anything like that. I'd always have music on in the kitchen. So anything I'm doing in the kitchen I generally tend to have music on. (Chris, 29)

There is an instrumental functionality to the use of music here that is similar to the way in which it is described in the workplace, though again there is also an affective element in that music 
listening tends to divert attention away from the more monotonous tasks. The difference is that there is more freedom for the participants to be flexible with how they use music within their sparetime routines, both in terms of what they are listening to and when they consume. This functionality is also evident in how music is used in exercise. The participants use music when they are running, lifting weights or doing other physical activities at the gym. The music is used to help overcome physical challenges that produce an enjoyable tension. The rhythm of the music can enhance adrenaline and also perhaps aid an imaginary channeling of energy or suppressed anger that is engendered from workplace practices and processes. Chris illustrates this when speaking about the adrenaline felt when listening to music and exercising at the same time:

Obviously you get a bit of a high after going for a run or going training or a good session in the gym. I generally tend to get, even if I've had a bad day or in a bad mood, fitness would always pick you up or get you to forget about it because you're thinking about getting through the next exercise or whatever. It kind of shifts you away from whatever mood you were in before. (Chris, 29)

Ciara uses exercise and music in a similar fashion. A specialised playlist is used to establish a rhythm in her running that helps her to de-stress from work pressures and engage in leisure practices that constitute more positive emotional flows:

I think running and music combined is a good switch-off. (Ciara, 28)

There is a greater sense of emotional tension, imagination and motility demonstrated in exercising with music as opposed to the experiences participants have of using music in nonsparetime activities or even sparetime routines. Furthermore, Chris and Ciara's experiences also 
indicate how music can be used to blur the boundaries between different spaces, in this case using the emotional tension from work to spur themselves on in intermediary activities.

\section{(De)Controlling mood: Leisure activities}

One of the key themes that can be identified in the findings presented thus far is the relationship between choice, space and control in consumption. The participants attempt to use music instrumentally across the non-sparetime and sparetime spectrums to facilitate an appropriate mood or improve performance at a particular task. Achieving this sense of control can help demarcate and transition space and also generate enjoyable tensions (e.g. the use of music for exercising). However, its routine use in these spaces does not facilitate the same pleasurable excitement that it does in defined leisure spaces/activities which engender the key characteristics of motility, sociability and mimetic tension to a greater level. We argue that this is because aspects of control that are a feature of consumption in the other spaces discussed are not as prevalent in the defined leisure space, in particular live music consumption. One of the reasons for this is because of the sociality involved. Elias and Dunning had sociable activities in mind when they initially conceived of their sociology of leisure. Our analysis mostly refers to individualised listening practices that have become routinised for many of the participants. Attending live music events allows individuals to share the emotional experience of music, reinforce social ties and collectively loosen social conformities in a setting that is more socially acceptable. This is of course often aided by the social adhesive of alcohol in addition to the music:

A gig is a night out with people who would like that band. And I would go to certain gigs with different people given the different genres. So it definitely helps stay in touch with 
these people. Or it helps because I used to go out on the lash [get drunk] with them and a gig is a good excuse to do that. (Niall, 28)

Alcohol, dancing and the social setting of a live music event (or even a pub or nightclub) facilitate a greater sense of the unexpected as the participants give up control of the usually highly individualised ways that music is consumed. This helps to generate a more exciting mimetic tension. However, maintaining an element of control is still important for listening to music in this way. Gordon, among others, expresses his frustrations with other people interfering with the experience of live events:

[going to gigs] is the main thing for me probably. You can't do anything else at a gig apart from listening to the band. Apart from them arseholes who take their phone out. Watching the gig through their phone. (Gordon, 29)

This is perhaps a legacy of becoming accustomed to having greater control over music through streaming applications. Consequently, for some participants, a sense of control regarding what they can expect in these settings is important and can be achieved by using streaming and information technology services to research what music they can expect to hear:

If we are going to gigs my best friend will send me links of new stuff before we go, a mix of something. (Gina, 22)

This of course has always been the case for people going to concerts. They listen to a band on the radio or hear the $\mathrm{CD}$ before deciding to buy a ticket. However, information provided by streaming applications allows participants to research an artist thoroughly and build expectations of a concert before committing to it: 
I have to like a band, listen to the band, and then I'd buy the ticket. I wouldn't go along to a gig, or I wouldn't be in a place where there'd be a gig on and then I'd go and listen to that band...I have Spotify, I can listen to the sound of the band by trawling through Spotify. (Niall, 28)

The control that is attained over the experience here can be used to facilitate the emotional 'decontrolling' element of the experience. In a similar way to attending a sporting event, knowing the players and the potential key moments of a match can heighten the emotional experience. The participants can experience the generation and release of emotional tension more effectively if they know when the chorus will come in or what popular songs are coming next. However, the use of these technologies removes some of the uncertainty and tension that is important to a leisure activity. Whether this diminishes or enhances the live music experience of those who prepare before attending is difficult to judge. However, for those who attend such events the spontaneity can create a sense of emotional tension that is very enjoyable:

A lot of gigs I've gone to are first time gigs, never really listened, gone in blind. And it's actually brilliant, I did that with a few bands and I ended up listening to them afterwards a lot. (Jay, 30)

Although this kind of experience was unusual in comparison to the rest of the participants, it is striking that when the sense of control over music consumption is relinquished how the emotional experience transforms somewhat to reflect the type of leisure practice that Elias and Dunning describe.

\section{Conclusion}


Music as a form of leisure offers multiple and flexible social and psychic functions which enables its consumption within a range of tasks across work, leisure and sparetime spaces. These affordances are shaped by technological developments such as internet streaming and privatised listening devices such as smartphones and earphones, but also structured by a broadening network of social interdependencies that include not only consumers, musicians, sound engineers and distributors, but increasingly computer scientists who design algorithms to individualise music recommendations to consumers. These recommendations are themselves based on a technological reduction of a myriad of music choices by vastly increasing music consumers, in an attempt to discern alignments of musical taste. While people still recommend artists to each other within their physically co-present and more intimate social networks, music choice and taste has been extended to incorporate the tastes of strangers, due to the emergence of new technologies which are themselves outcomes of knowledge and expertise flowing from broadening figurations of computer and engineering specialists.

This expansion of choice, framed by the choices of others, offers increasing opportunities for the integration of leisure practices over diverse social spaces, thereby loosening and blurring the boundaries of these spaces. However, such choices are also shaped by the structure of social relations in either work or sparetime activities. Elias and Dunning argue that organised leisure, in a more controlled decontrolling of emotional standards, is a means of emotional refreshment within the context of increasing routinisation and emotional self-control in work activities, and indeed sometimes sparetime activities that also entail routine procedures oriented towards the needs of others and therefore feel like work. The affordances of new technologies have made the integration of routine tasks and more emotionally fulfilling experiences easier. But here we must 
assess the possibilities and functions of music listening along a spectrum of social dependencies that require synchronous interaction on the one hand, and asynchronous activity on the other. In work spaces, people sometimes can listen to music, but the meaning and function of this practice depends on whether the worker could be called upon to engage in social dialogue and coordination of tasks with others, particularly if they are physically co-present, as in the case of open office environments. The meaning of music listening as a leisure practice can also change due to its instrumental use for improved performance or concentration at work, or to screen out the noise of other people. The practice of integrating 'leisure' at work also depends upon the fluid power balances between colleagues, and in particular the formal and informal hierarchical organisational structures that shape, over time, norms of conduct at work.

Music listening can also blur spaces and tasks in non-work sparetime activities that are oriented to others. Household chores and family obligations often take on the character of some types of work due to their routine nature and implicit focus on the expectations of others (though these do not have to be articulated depending on the degree of internalisation in the habitus). Music listening as a leisure practice allows the simultaneous completion of other more mundane tasks, and therefore transforms the emotional experience of routine. The emotional flow combines different emotions at the same time, based on a more self-referential (in terms of pleasurable feeling opportunities) experience. Internet streaming and mobile devices also allow more frequent alteration of emotional stimuli, as playlists can be changed with relative ease, or playlists devised by other people can be selected to increase unpredictability. People have become less dependent on a relatively static set of musicians (compared to their physical record collection for example), and this in turn has depended upon increasing numbers of like-minded 
(or like-feeling) consumers embracing new technologies thereby making the distributive platform more attractive to more musicians (the producers of these leisure offerings that interact with the psychic and social processes of listeners to generate emotions), notwithstanding issues concerning the low financial incentive of having music streamed.

New technologies of music distribution have also made music listening potentially more continuous, but this can flatten the emotional experience of listening as leisure. Elias and Dunning speculate that people would be unlikely to enjoy the emotional refreshment of leisure if it became permanent. The emotional experience seems to require more transient rhythms of different activities in order to enhance the emotional experience of novelty. Similarly, we find that people are drawn to the more sociable experience of listening to music in live performance settings, which are beyond the control of any single individual. Here individual choice is somewhat diminished because each person cannot entirely predict the actions of physically copresent others in the context of more defined spaces for leisure that permit controlled decontrolling. Even here, however, the relinquishing of individual control combined with high expectation can lead to emotional frustration rather than refreshment. Elias (2018) noted 60 years ago that the working habitus often seeps into leisure experiences. While his anticipated increase in leisure time has not yet come to fruition, new and broadening interdependences in the form of technology would appear to have generated varying degrees of work-leisure integration.

\section{Endnotes}

${ }^{1}$ This increase is calculated by using a metric that allows for sales in all formats to be measured on a comparable basis to streaming. 


\section{References}

Adorno, T. (2006). Philosophy of modern music, translated by R. Hullot-Kentor. Minesota:

University of Minesota Press.

Author A and Author C

Author A and Author B

British Phonographic Industry (2017). UK record labels trade income at five-year high following $5.1 \%$ growth in 2016 '. Available at: www.bpi.co.uk/media-centre/uk-record-labels-tradeincome-at-five-year-high-following-51-growth-in-2016.aspx.

Bull, M. (2000). Sounding out the city: Personal stereos and the management of everyday life. Oxford: Berg.

Bull, M. (2006). Investigating the culture of mobile listening: From Walkman to iPod. In: K. O'Hara and B. Brown (eds), Consuming music together: Social and collaborative aspects of music consumption technologies (pp. 131-149). Dorrecht: Springer.

Chartered Institute of Personnel and Development. (2016). Growing the health and well-being agenda: From first steps to full potential. Available at:

https://www.cipd.co.uk/knowledge/culture/well-being/health-agenda-report

DeNora, T. (2000). Music in everyday life. Cambridge: Cambridge University Press.

Dunning, E. (1997). Sport in the Quest for Excitement: Norbert Elias"s Contributions to the Sociology of Sport. Group Analysis, 30(4), 477-87.

Elias, N. (2012[1939]). On the process of civilisation. Dublin: University College Dublin Press. 
Elias, N. (2008[1986]). Introduction. In: N. Elias and E. Dunning (eds.), The quest for excitement: sport and leisure in the civilising process (pp. 3-43). Dublin: University College Dublin Press.

Elias, N. (2018). Spontaneity and self-consciousness. In: J. Haut, P. Dolan, D. Reicher and R. Sánchez García (eds.), Excitement processes: Norbert Elias 's unpublished works on sports, leisure, body, culture (pp. 23-76). Wiesbaden: Springer.

Elias, N., \& Dunning, E. (2008a). The quest for excitement: Sport and leisure in the civilising process. Dublin: University College Dublin Press.

Elias, N., \& Dunning, E. (2008b). Leisure in the sparetime spectrum. In: Elias N, Dunning E The quest for excitement (pp. 73-106). Dublin: University College Dublin Press.

Giesler, M. (2008). Conflict and compromise: Drama in marketplace evolution. Journal of Consumer Research, 34(6), 739-753.

Gregory, A. H. (1997).The roles of music in society: The ethnomusicological perspective. In: D. J. Hargreaves (ed.), The social psychology of music (pp. 123-140). Oxford: Oxford University Press.

Halnon, B. K. (2004). Inside shock music carnival: Spectacle as contested terrain. Critical Sociology, 30(3), 743-779.

Hargreaves, D. J., North, A.C. (1999). The functions of music in everyday life: Redefining the social in music psychology. Psychology of Music, 27(1), 71-83.

Heye, A \& Lamont, A. (2010). Mobile listening situations in everyday life: The use of MP3 players while travelling. Musicae Scientiae, 14(1), 95-120. 
Jones, S.C. \& Schumacher, T.G. (1992). Muzak: On functional music and power. Critical Studies in Media, 9(2), 156-169.

Korczynski, M. \& Jones, K. (2006). Instrumental music? The social origins of broadcast music in British factories. Popular Music, 25(2), 145-164.

Léveillé, G.H. (2017). Drawing listener attention in popular music: Testing five musical features arising from the theory of attention economy. Musicae Scientiae, Prepublished March 1, 2017. doi: $10.1177 / 1029864917698010$

Magaudda, P. (2011). When materiality "bites back": Digital music consumption practices in the age of dematerialization. Journal of Consumer Culture, 11(1), 15-36.

Maguire, J.A. (2011). Welcome to the pleasure dome?: Emotions, leisure and society. Sport in Society 14(7-8), 913-926.

Merriam, A.P. (1964). The anthropology of music. Chicago: Northwestern University Press.

Merriam, S. (2009). Qualitative Research: A Guide to Design and Implementation. San Francisco: John Wiley \& Sons.

North, A.C. \& Hargreaves, D.J. (2000). Musical preferences during and after relaxation and exercise. The American Journal of Psychology, 113(1), 43-67.

Oldham, G.R., Cummings, A., Mischel, L.J., Schmidtke, J.M., \& Zhou, J. (1995). Listen while you work? Quasi-experimental relations between personal-stereo handset use and employee work responses. Journal of Applied Psychology, 80(5), 547-64. 
Pink, S. \& Fors, V. (2017). Being in a mediated world: Self-tracking and the mind-bodyenvironment. Cultural Geographies, 24(3), 375-388.

Rojek, C. (2005). P2P leisure exchange: Net banditry and the policing of intellectual property. Leisure Studies, 24(4), 357-369.

Schäfer, T., Sedlmeier, P., Städtler, C., \& Huron D. (2013). The psychological functions of music listening. Frontiers in Psychology, 4, 511.

Sloboda, J.A. (2005). Exploring the musical mind: Cognition, emotion, ability, function. Oxford, UK: Oxford University Press.

Sonnentag, S., Arbeus, H., Mahn, C., \& Fritz, C (2014). Exhaustion and lack of psychological detachment from work during off-job time: Moderator effects of time pressure and leisure experiences. Journal of Occupational Health Psychology, 19(2), 206-216.

Spiggle, S. (1994). Analysis and interpretation of qualitative data in consumer research. Journal of Consumer Research, 21, 491-503.

Stebbins, R.A. (2015). Serious Leisure: A Perspective for Our Time. New Brunswick: Transaction Publishers.

Thing, L.F. (2016). Classic book review: Quest for excitement: Sport and leisure in the civilising process. Annals of Leisure Research, 19(3), 368-373.

Wlömert, N., \& Papies, D. (2016). On-demand streaming services and music industry revenues Insights from Spotify's market entry. International Journal of Research in Marketing, 33(2), $314-327$. 